\title{
Rectal gel application of Withania somnifera root extract expounds anti-inflammatory and muco- restorative activity in TNBS-induced Inflammatory Bowel Disease
}

Pankaj Pawar ${ }^{1,2}$, Suhit Gilda', Siddhesh Sharma', Suresh Jagtap ${ }^{1,2}$, Anant Paradkar ${ }^{1}$, Kakasaheb Mahadik Prabhakar Ranjekar ${ }^{1,2}$ and Abhay Harsulkar ${ }^{1, *^{*}}$

\begin{abstract}
Background: Inflammatory Bowel Disease (IBD) is marked with chronic inflammation of intestinal epithelium driven by oxidative stress. Traditional treatments with plant extracts gained renewed interest due to their ability to ameliorate the multi factorial conditions like inflammation. We investigated the beneficial effects of Withania somnifera in Trinitro Benzyl Sulfonic Acid (TNBS) induced experimental IBD through a rectally applicable formulation.

Methods: The study included (i) preparation of gel formulation from aqueous Withania somnifera root extract (WSRE), (ii) biochemical assays to determine its performance potential, (iii) testing of formulation efficacy in TNBSinduced IBD rat model, and (iv) histo-patholgical studies to assess its healing and muco-regenerative effect in IBDinduced rats. For this purpose, concentration dependant antioxidant activity of the extracts were evaluated using biochemical assays like (a) inhibition of lipid peroxidation, (b) $\mathrm{NO}$ scavenging, (c) $\mathrm{H}_{2} \mathrm{O}_{2}$ scavenging, and (d) ferric reducing power assay.
\end{abstract}

Results: The extract, at $500 \mu \mathrm{g} / \mathrm{ml}$, the highest concentration tested, showed $95.6 \%$ inhibition of lipid peroxidation, $14.8 \% \mathrm{NO}$ scavenging, $81.79 \% \mathrm{H}_{2} \mathrm{O}_{2}$ scavenging and a reducing capacity of 0.80 . The results were comparable with standard antioxidants, ascorbic acid and curcumin. WSRE treatment positively scored on histopathological parameters like necrosis, edema, neutrophil infiltration. The post treatment intestinal features showed restoration at par with the healthy intestine. In view of these results, gel formulation containing an aqueous extract of $W$. somnifera, prepared for rectal application was tested for its anti-inflammatory activity in TNBS-induced rat models for IBD. Commercially available anti-inflammatory drug Mesalamine was used as the standard in this assay.

Conclusions: Dose of the rectal gel applied at 1000 mg of WSRE per kg rat weight showed significant mucorestorative efficacy in the IBD-induced rats, validated by histo-pathological studies.

\section{Background}

Withania somnifera (Dunal), also known as Ashwagandha, is an important member of family Solanaceae, utilized as a medicine for more than 2500 years in Indian medicinal classic "Ayurveda" [1]. Roots of this plant are considered most active for therapeutic

\footnotetext{
* Correspondence: aharsulkar@yahoo.com

'Poona College of Pharmacy, Bharati Vidyapeeth University, Erandwane, Pune 411023 , India

Full list of author information is available at the end of the article
}

purposes by virtue of significant accumulation of active constituents, withanolides [2]. Several withanolides with cyclooxygenase inhibitory and lipid peroxidation inhibitory activity were isolated from leaves and fruits of W. somnifera [3,4], besides anti-inflammatory [5], antitumor [6] and antioxidant [7] activities. Immunomodulatory role of $W$. somnifera roots and anti-inflammatory activity using adjuvant-induced arthritic rat models was also demonstrated [8,9]. Luvone et al [10] had observed that methanolic extracts of $W$. somnifera roots turns-on

\section{Biomed Central}


the synthesis of inducible nitric oxide synthase expression by acting at transcriptional level resulting in increased production of NO by macrophage, which was attributed to immunomodulatory and anti-inflammatory activity. Considering the various biological activities, roots of W. somnifera can potentially be utilized for the effective treatment of various inflammatory conditions.

Inflammatory bowel disease (IBD) encompasses (i) various conditions that result in chronic inflammation of small and/or large intestine, alike in young, adults and old, (ii) Ulcerative Colitis (UC), characterized by chronic mucosal and sub-mucosal inflammation of large intestine and rectum and (iii) Crohn's Disease (CD), which is chronic transmural inflammation of all/any part of the gastro-intestinal tract involving mucosa, submucosa, muscular and connective tissue [11]. However, IBD, UC and CD are considered together because of similarities in their characteristics, pathology, complications, investigations, and treatment [12].

Etiology of IBD largely remains unknown [13]; however, development of tissue injury is attributed largely to distorted immune system and reactive oxygen species (ROS) [14]. Sustained production of reactive oxygen and nitrogen species is due to dysfunction of immune system is believed to play an important role in the development of intestinal colon injury [15]. It is therefore, logical to treat this disorder by controlling oxidative stress. Logically, antioxidant chemicals have been the main therapeutic strategy in IBD for last 50 years [16]. The popular treatment of IBD involves use of (a) 5-aminosalicylate based compounds, which are potent ROS scavengers [17], (b) broad spectrum antibiotics, (c) steroids and immuno-suppressants. These drugs are typically associated with side effects like nausea, anorexia, dizziness, headache, cytopenia, fever, myalgia, abnormal liver function, pleropericarditis, renal insufficiency and pulmonary toxicity. Plants are considered to be a goldmine to tackle complex inflammatory conditions with minimum of side effects. The effective herbs with antioxidant activity have been recently reviewed [18]. Numbers of reports are available on anti-inflammatory activities of plant-derived crude extracts or compounds derived from different plants. For example, curcumin has been widely investigated for the treatment of experimental colitis to decrease inflammation in therapeutic dosages [19-22]. Similarly, formulation containing a mixture of four herbal drugs (Aegle marmeloes, Coriandrum sativam, Cyperus rotundus and Vetiveria zinzaniods) showed significant inhibitory activity comparable with the standard drug prednisolone [12] against IBD induced in experimental animal models. It has become, therefore, imperative to search for safer alternative strategies that modulate the entire inflammatory pathway.
Withania somnifera is a unique plant where a wide range of activities has been demonstrated including antagonism with several pro-inflammatory factors and immunomdulation. In Ayurveda, enema of W. somnifera water extract is prescribed for intestinal ulcers, irritable bowel and rectal bleeding. All these attributes encouraged us to investigate its usefulness in the treatment of IBD [23]. Ours is the first report where aqueous extract of W. somnifera roots was assessed in Trinitro Benezyl Sulfonic Acid (TNBS) induced IBD in rat model, using formulation designed for rectal application. Mucosal adhesion of the formulation facilitated precise application of the extract on intestinal lesions.

\section{Methods}

\section{Plant material and extract preparation}

Authenticated roots of $W$. somnifera were procured from Green Pharmacy, Pune. Its aqueous extract was prepared by suspending $15 \mathrm{gm}$ root powder in $100 \mathrm{ml}$ distilled water, followed by shaking $\left(150 \mathrm{rpm}\right.$, at $60^{\circ} \mathrm{C}$, for $24 \mathrm{~h}$ ). The extract was filtered and clear suspension utilized for the antioxidant assays. Standardization of the extract was done by HPTLC method for quantification of Withanolide D using standard lab protocol.

\section{Antioxidant assays}

Five different biochemical assays were undertaken to assess the antioxidant activity of W. somnifera aqueous roots extract (WSRE)

\section{Anti-lipid peroxidation activity}

Anti-lipid peroxidation potential of WSRE was determined by estimating the inhibition of thiobarbituric acid reactive species (TBARS). Lipid peroxidation was initiated by adding $100 \mu \mathrm{l}$ of $1 \mathrm{mM}$ ferric chloride in $10 \% \mathrm{w} / \mathrm{v}$ colon tissue homogenate. Malonyldialdehyde (MDA) generated by the oxidation of polyunsaturated fatty acids upon reaction with two molecules of thiobarbituric acid (TBA) yielded a pink red complex, which was measured at $532 \mathrm{~nm}$, from which \% inhibition of lipid peroxidation by WSRE was calculated. In practice, mixtures containing $0.5 \mathrm{ml}$ of tissue homogenate, $1 \mathrm{ml}$ $0.15 \mathrm{M} \mathrm{KCl}$ and $0.5 \mathrm{ml}$ different concentrations of WSRE were prepared. Lipid peroxidation was initiated by adding $100 \mu \mathrm{l}$ of $1 \mathrm{mM}$ ferric chloride. Incubated at $37^{\circ} \mathrm{C}$ for $30 \mathrm{~min}$. The reaction was stoped by adding 2 $\mathrm{ml}$ ice-cold $0.25 \mathrm{~N} \mathrm{HCl}$ (containing 15\% trichloroacetic acid (TCA), $0.38 \%$ TBA and $0.2 \mathrm{ml} 0.05 \%$ butylated hydroxyl toluene (BHT)). The reaction mixture was heated at $80^{\circ} \mathrm{C}$ for $60 \mathrm{~min}$, cooled, centrifuged $(5000 \mathrm{~g}$ $\approx 6900 \mathrm{rpm}, 15 \mathrm{~min}$ ). Absorbance of the supernatant was measured at $532 \mathrm{~nm}$ against a blank, which contained all reagents except colon homogenate and WSRE. Identical experiments were performed to determine the normal (without drug and $\mathrm{FeCl}_{3}$ ) and induced (with the 
drug) lipid peroxidation level in the tissue. The percentage of anti-lipid peroxidation effect (\%ALP) was calculated by the following formula [24].

$$
\% \mathrm{ALP}=\left[\mathrm{A}_{\mathrm{Fecl} 3}-\mathrm{A}_{\text {test. }} / \mathrm{A}_{\mathrm{Fec} 3}-\mathrm{A}_{\mathrm{Normal}}\right] \times 100
$$

Where, $\mathrm{A}_{\mathrm{FeCl} 3}$ : Absorbance of $\mathrm{FeCl}_{3}, \mathrm{~A}_{\mathrm{Normal}}$ : Absobance of control reaction,

$\mathrm{A}_{\text {test }}$ : Absorbance of test reaction

\section{Nitric oxide (NO) scavenging activity}

Nitric oxide radical inhibition was estimated using Griess-Illosvoy reaction principle. In this protocol, a reaction mixture $(6 \mathrm{ml})$ containing sodium nitroprusside (10 mM, $2 \mathrm{ml})$, phosphate buffer saline (PBS) $(0.5 \mathrm{ml})$ and different concentrations of extract or standard solution was prepared. A reaction control without test compound but equivalent amount of methanol was maintained. Incubation was carried out at $25^{\circ} \mathrm{C}$ for 150 min, followed by treating $0.5 \mathrm{ml}$ of the reaction mixture with $1 \mathrm{ml}$ Griess reagent $A$. In the next step, $1 \mathrm{ml}$ of Griess reagent B was added and incubated at $25^{\circ} \mathrm{C}$ for $60 \mathrm{~min}$. Absorbance was measured at $540 \mathrm{~nm}$. The \% inhibition was calculated using the formula [25].

$$
\% \text { Inhibition }=\left[\left(A_{\text {cont }}-A_{\text {test }}\right) /\left(A_{\text {cont }}\right)\right] \times 100
$$

Where $\mathrm{A}_{\text {cont }}$ - absorbance of the control reaction

$A_{\text {test }}$ - absorbance of reaction with the extract.

\section{Hydrogen peroxide scavenging activity}

Ability of the extract to scavenge $\mathrm{H}_{2} \mathrm{O}_{2}$ was determined as per Ruch et al [26]. A solution of $\mathrm{H}_{2} \mathrm{O}_{2}$ was prepared in PBS (pH 7.4) and its concentration determined spectrophotometrically. The reaction mixture $(0.9 \mathrm{ml})$ containing extract $(0.3 \mathrm{ml})$ and $\mathrm{H}_{2} \mathrm{O}_{2}(0.6 \mathrm{ml}$ each $)$ in $\mathrm{PBS}$ were incubated at ambient temperature for $10 \mathrm{~min}$ and its absorbance at $260 \mathrm{~nm}$ was determined $10 \mathrm{~min}$ later against a blank solution containing PBS without $\mathrm{H}_{2} \mathrm{O}_{2}$. The $\% \mathrm{H}_{2} \mathrm{O}_{2}$ scavenging of both, the extract and standard were calculated as follows:

$$
\mathrm{H}_{2} \mathrm{O}_{2} \text { Scavenged }(\%)=\left[\left(A_{\text {cont }}-A_{\text {test }}\right) /\left(A_{\text {cont }}\right)\right] \times 100
$$

Where, $\mathrm{A}_{\text {cont }}$ : Absorbance of control reaction, $\mathrm{A}_{\text {test: }}$ : Absorbance of test reaction.

\section{Evaluation of the reducing power}

The reducing power of the extract was measured by the transformation of $\mathrm{Fe}^{3+}$ to $\mathrm{Fe}^{2+}$ in the presence of different concentrations of extract at $700 \mathrm{~nm}$ as per Mau [27]. It involved mixing (a) $1 \mathrm{ml}$ aliquot of different concentrations of WSRE $(250-2500 \mu \mathrm{g} / \mathrm{ml})$ with $2.5 \mathrm{ml}$ phosphate buffer ( $\mathrm{pH} 6.8$ ) and $2.5 \mathrm{ml}$ potassium ferricyanide, (b) incubating it at $50^{\circ} \mathrm{C}$ for $20 \mathrm{~min}$, (c) arresting the reaction by addition of $2.5 \mathrm{ml}$ TCA (d) centrifuging at $3000 \mathrm{rpm}$ for $10 \mathrm{~min}$, (e) taking $2.5 \mathrm{ml}$ supernatant, diluting with $2.5 \mathrm{ml}$ distilled water, (f) adding $0.5 \mathrm{ml}$ of $\mathrm{FeCl}_{3}$ solution, and (g) measuring absorbance at $700 \mathrm{~nm}$. Increased absorbance of the reaction mixture indicates increased reducing power.

\section{Induction of experimental colitis}

The animal experimental procedures were in accordance with the regulation of institutional animal ethical committee, Poona College of Pharmacy, Bharati Vidyapeeth University, (CPCSEA/47/2007-08). Wistar rats weighing approximately 200-250 g each of either sex were distributed in four different groups $(n=6)$, i.e. healthy control, negative control, positive control and test group were housed in institutional animal house with controlled temperature $\left(25^{\circ} \mathrm{C}\right)$. TNBS/ethanol induced colitis in the rat was established according to Elson et al [28]. After overnight fasting, each rat was lightly anaesthetised with diethyl ether, and a polyethylene cannula $(4 \mathrm{~mm}$ diameter) was inserted into the lumen of the colon and advanced so that its tip was $6-8 \mathrm{~cm}$ proximal to the anus. Initially, each rat was lavaged with $2 \mathrm{ml}$ of saline for enema followed by manual palpation of the abdomen to remove the fecal matter, if any. Next, TNBS $(100 \mathrm{mg} /$ $\mathrm{kg}$ of rat weight) dissolved in $50 \%$ ethanol $(\mathrm{v} / \mathrm{v})$ was instilled into the colon lumen (only $0.25 \mathrm{ml}$ ) through the rubber catheter, and the rat was maintained in a head-down position for 20 seconds to limit the expulsion of solution. From the fourth day up to $14^{\text {th }}$ day treatment was given by rectal administration of thermoreversable gel. Animals were maintained on water and diet ad libitum through out.

\section{Preparation of gel for rectal application}

The gel preparation involved (a) use of sufficient amount of pluronic F127 to yield desired 20 (\% w/w) gel, slowly added to cold $\left(5^{\circ} \mathrm{C}\right)$ water with constant stirring, and (b) refrigeration of dispersion until a clear solution was formed. Concentration of WSRE was maintained such as to deliver $1 \mathrm{gm} / \mathrm{kg}$ body weight of the IBD-rats per day (effective concentration of withanolide $\mathrm{D}$ in the formulation was $0.0336 \% \mathrm{w} / \mathrm{w}$ ) [29].

\section{Assessment of severity of colitis}

At the end of the experiments, rats were sacrificed by cervical dislocation, the colon excised, opened longitudinally, and washed in saline. Macroscopic damage was assessed on the basis of semi-quantitative scoring system [30], which takes into account the area of inflammation and presence/absence of ulcers as described by Ukil et al [20] (No ulcer, no inflammation: 0; No ulcer, local hyperemia: 1 ; Ulceration without hyperemia: 2 ; Ulceration and inflammation at one site only: 3; Ulceration and inflammation at two or more sites: 4; and Ulceration extending more than $2 \mathrm{~cm}$ : 5). A $10 \mathrm{~cm}$ segment of colon was excised and weighed as an increase in weight is seen after induction of colitis. Further, these weights 
were compared with different groups to give an idea about weight recovery and malondialdehyde levels determined in each tissue, which served as an indicator of lipid peroxidation.

\section{Microscopic assessment of colitis}

Histo-pathological studies of the colon were carried out at Local Pathology Laboratory, by an expert cyto-histopathologist by staining the sections with haematoxylin and eosin and taking their colored microscopic images, with resolution 10X-45X using a trinocular camera.

\section{Statistical analysis}

Results are expressed as mean \pm standard deviation of $n$ observations. Analysis of variance $(\mathrm{P}<0.05)$ to determine the statistical significance of inter-group comparisons, was considered statistically significant. Macroscopic and microscopic scores for colon erosion for the W. somnifera -pretreated groups were compared against those for the TNBS-treated group with a oneway ANOVA and Tukey test.

\section{Results}

Antioxidant potential of aqueous extracts, determined biochemically using various assays, exhibited the following profiles.

\section{Anti-lipid peroxidation activity}

Inhibitory effects of ascorbic acid and WSRE in the concentration range 100 to $500 \mu \mathrm{g} / \mathrm{ml}$, on TBARS formed in rat colon induced by $\mathrm{FeCl}_{3}$ in vitro were studied. It was lowest $(12.67 \%)$ at $100 \mu \mathrm{g} / \mathrm{ml} \mathrm{WSRE}$ and gradually increased to $95.59 \%$ at $500 \mu \mathrm{g} / \mathrm{ml}$, thus showing increase in the activity with an increase in the concentration. In ascorbic acid, anti-lipid peroxidation inhibition activity at $100 \mu \mathrm{g} / \mathrm{ml}$ was far higher (85.71\%) than WSRE; it was six fold more than that of WSRE at the same concentration. It showed $99.97 \%$ inhibition of lipid peroxidation at $500 \mu \mathrm{g} / \mathrm{ml}$ (Table 1). Unpaired T-test showed significant $P$ value of 0.0411 .

\section{Nitric oxide scavenging activity}

WSRE at $100 \mu \mathrm{g} / \mathrm{ml}$ concentration showed $10.55 \% \mathrm{NO}$ scavenging activity, which increased to 14.30 at $200 \mu \mathrm{g} /$ $\mathrm{ml}$, beyond which no significant increase was noted with further increase in concentrations $\left(\mathrm{IC}_{50}=58.70 \mu \mathrm{g} / \mathrm{ml}\right)$ (Table 1). Curcumin, used as a positive control at 50 $\mu \mathrm{M}$ concentration showed $11.79 \%$ NO scavenging, almost comparable with that by WSRE.

\section{Hydrogen peroxide scavenging activity}

Ascorbic acid, used as a standard, at $10 \mu \mathrm{g} / \mathrm{ml}$ concentration showed $98.95 \%$ inhibition (data not shown in table). Hydrogen peroxide scavenging activity of the extract was concentration-dependent; about 59.84\% $\mathrm{H}_{2} \mathrm{O}_{2}$ scavenging activity at $100 \mu \mathrm{g} / \mathrm{ml}$ concentration increased up to $81.79 \%$ as a function of increase in the concentration of the extract to $500 \mu \mathrm{g} / \mathrm{ml}$ (Table 1), indicating that aqueous extracts of roots of W. somnifera are good scavenger of peroxide radicals.

\section{Evaluation of the reducing potential}

As expected from the literature, the WSRE exhibited significant reductive potential towards $\mathrm{Fe}^{3+}$ to result into $\mathrm{Fe}^{2+}$. It was about $0.5 \mathrm{At} 100 \mu \mathrm{g} / \mathrm{ml}$ concentrations, which was at par with the standard ascorbic acid. Further, it showed a clear dose dependent increase in reducing power (Table 1).

\section{Pharmacological screening}

Rectal gel formulation was tested for its gelation and gel melting temperatures after addition of the extract. Bioadhesive strength of the formulation was measured on goat colon (Data not shown).

Malonyldialdehyde (MDA) levels were measured as an indicator of lipid peroxidation. In rats without any treatment (healthy control) average MDA levels were 11.63, far lower as compared to those in rats subjected to TNBS enema and no drug treatment (22.85), whereas rats treated with W. somnifera formulation (WSREF) (test control) showed significant decrease (18.15) in MDA levels, comparable with the mesalamine (standard drug) treated rats (18.66) (Table 2).

\section{Macroscopic and histological evaluation}

TNBS enema resulted in pronounced hemorrhagic and ulcerative lesions in the colon as observed after induction up to 8 days. Macroscopic examination of the

Table 1 Comparative Antioxidant Free radical scavenging and anti-inflammatory activity of Withania somnifera

\begin{tabular}{|c|c|c|c|c|c|c|}
\hline \multirow[b]{2}{*}{ Conc. $(\mu \mathrm{g} / \mathrm{ml})$} & \multicolumn{2}{|c|}{$\%$ LPO Inhibition } & \multirow{2}{*}{$\begin{array}{l}\% \text { NO Scavenging } \\
\text { Withania somnifera }\end{array}$} & \multirow{2}{*}{$\begin{array}{c}\% \mathrm{H}_{2} \mathrm{O}_{2} \text { Scavenging } \\
\text { Withania somnifera }\end{array}$} & \multicolumn{2}{|c|}{ Reducing power } \\
\hline & Withania somnifera & Ascorbic acid & & & Withania somnifera & Ascorbic acid \\
\hline 100 & $12.67 \pm 0.83$ & $85.71 \pm 0.72$ & $10.55 \pm 0.97$ & $59.84 \pm 0.79$ & $0.4996 \pm 1.34$ & $0.4177 \pm 1.53$ \\
\hline 200 & $51.73 \pm 1.26$ & $91.54 \pm 0.98$ & $14.30 \pm 0.86$ & $63.52 \pm 0.85$ & $0.5247 \pm 1.21$ & $0.5647 \pm 1.04$ \\
\hline 300 & $65.02 \pm 1.13$ & $96.05 \pm 0.86$ & $14.41 \pm 0.93$ & $73.59 \pm 0.98$ & $0.6137 \pm 0.95$ & $0.6804 \pm 1.02$ \\
\hline 400 & $75.70 \pm 1.23$ & $99.09 \pm 0.84$ & $14.75 \pm 0.96$ & $76.30 \pm 1.13$ & $0.7053 \pm 0.89$ & $0.7106 \pm 1.21$ \\
\hline 500 & $95.59 \pm 0.56$ & $99.97 \pm 1.36$ & $14.77 \pm 1.13$ & $81.79 \pm 1.23$ & $0.7972 \pm 0.58$ & $0.8090 \pm 0.96$ \\
\hline
\end{tabular}


Table 2 Malondialdehyde levels as an indicator of lipid peroxidation

\begin{tabular}{ccccc}
\hline Lipid peroxidation in rat intestine & Healthy control & Positive control & Negative control & WSAE* treated \\
\hline 1 & 11.65 & 18.52 & 23.68 & 17.79 \\
\hline 2 & 12.42 & 17.26 & 24.3 & 19.03 \\
\hline 3 & 9.63 & 19.39 & 22.34 & 19.66 \\
\hline 4 & 13.53 & 18.3 & 21.76 & 16.68 \\
\hline 5 & 12.1 & 19.92 & 22.88 & 18.52 \\
\hline 6 & 10.46 & 18.59 & $\mathbf{2 2 . 8 5}$ & 17.23 \\
\hline AVG $^{*}$ & $\mathbf{1 1 . 6 3}$ & $\mathbf{1 8 . 6 6}$ & $\mathbf{1 8 . 1 5}$ \\
\hline STDV * $^{*}$ & $\mathbf{1 . 4 0 1}$ & $\mathbf{0 . 9 2 0}$ & $\mathbf{0 . 9 6 9}$ & $\mathbf{1 . 1 2 5}$ \\
\hline
\end{tabular}

Abbreviation: ${ }^{*}=$ Withania somnifera aqueous extract

\# = Average

** $=$ Standard deviation

affected colon and rectum revealed significant erosion of mucosal lining and severe ulceration often indicated as fecal occult blood. The histological features included (a) transmural necrosis, (b) edema and (c) diffused leucocytes infiltration of the sub-mucosa. Treatment of rats with WSREF ( $0.5 \mathrm{ml}$ daily, containing $1 \mathrm{~g} / \mathrm{kg}$ body weight) resulted in a significant decrease in the extent and severity of the injury of large intestine as evidenced by macroscopic damage score in Table 3 as well as histopathological assessment as in Figure 1. In healthy control (rats without any treatment), (i) intestinal crypts were evenly spaced, dipping down unto muscularis and (ii) lamina propria mucosae showed usual number of lymphocytes, plasma cells as well as eosinophils (Figure 1a). In negative control (rats treated with TNBS only), mucosa showed (i) ulceration, (ii) crypts were obligated, (iii) lamina propria marked with edema and (iv) infiltration by eosinophils as well as neutrophils (Figure 1b), while the test control (IBD induced rats treated with WSREF) mucosa showed (i) normal crypts, and (ii) lamina propria with usual number of mononuclear inflammatory cells (Figure 1c). In positive control (IBDinduced rats treated with mesalamine), mucosal crypts showed slight distortion and both edema and lamina propria, showed infiltration by neutrophils and eosinophils (Figure 1d).

Table 3 Effect of various treatments on macroscopic score analysis

\begin{tabular}{|c|c|c|c|c|c|c|c|c|}
\hline \multirow[t]{2}{*}{ Group name } & \multicolumn{6}{|c|}{ Score rate } & \multirow[t]{2}{*}{$\mathrm{N}^{*}$} & \multirow[t]{2}{*}{ Mean } \\
\hline & 0 & 1 & 2 & 3 & 4 & 5 & & \\
\hline $\mathrm{HC}^{* *}$ & 5 & 1 & 0 & 0 & 0 & 0 & 6 & 0.16 \\
\hline $\mathrm{NC}$ & 0 & 1 & 1 & 2 & 2 & 0 & 6 & 2.83 \\
\hline $\mathrm{TC}$ & 0 & 3 & 2 & 1 & 0 & 0 & 6 & 1.60 \\
\hline$\overline{P C}$ & 0 & 2 & 2 & 2 & 0 & 0 & 6 & 2.00 \\
\hline
\end{tabular}

The observed inflammatory changes of the large intestine were associated with an increase in the weight of colon (Figure 2) as well as significant decrease in the body weight as compared to control rat (Figure 3). In contrast, no significant increase in the colon weight was found in the TNBS-treated rats on treatment with WSRE and marketed formulation of mesalamine. Moreover, treatment with these formulation dosages significantly reduced the loss in body weight, which correlated well with the amelioration of colon injury. The above data was subjected to statistical treatment by Tukey test and $\mathrm{p}$ values were obtained. The $\mathrm{p}$ value $<0.001$ for $W$. somnifera and standard group was highly significant; suggesting that rats treated with $W$. somnifera rectal gel formulation showed marked recovery.

\section{Discussion}

IBD is a common gastro-intestinal disorder marked with chronic inflammation of intestinal epithelium, damaging mucosal tissue and manifests into several intestinal and extra-intestinal symptoms, mainly related to oxidative stress, inflammation and autoimmune type.

TNBS-induced model is an experimental model of Th 1, like gut inflammation, mimics human Crohn's Disease and is widely used to investigate IBD [28]. TNBS enema develops hapten-induced delayed type hypersensitivity and results in the development of chronic colitis involving granuloma with infiltration of inflammatory cells in all layers of the intestine. This is due to TNBS-induced over expression of IL-12, IFN- $\gamma$ and IL-2, which supports the study that inducible colitis is due to Th-type 1 response [31]. Ilan et al. [32] studied the involvement of immune system in the pathogenesis of IBD after observing the similarities between human disease and TNBS-induced colitis. Their study revealed that IBD could be considered as an imbalance between pro-inflammatory and antiinflammatory mediators. Monocytes/macrophages, polymorphonuclear leucocytes (PMNs) and endothelial 


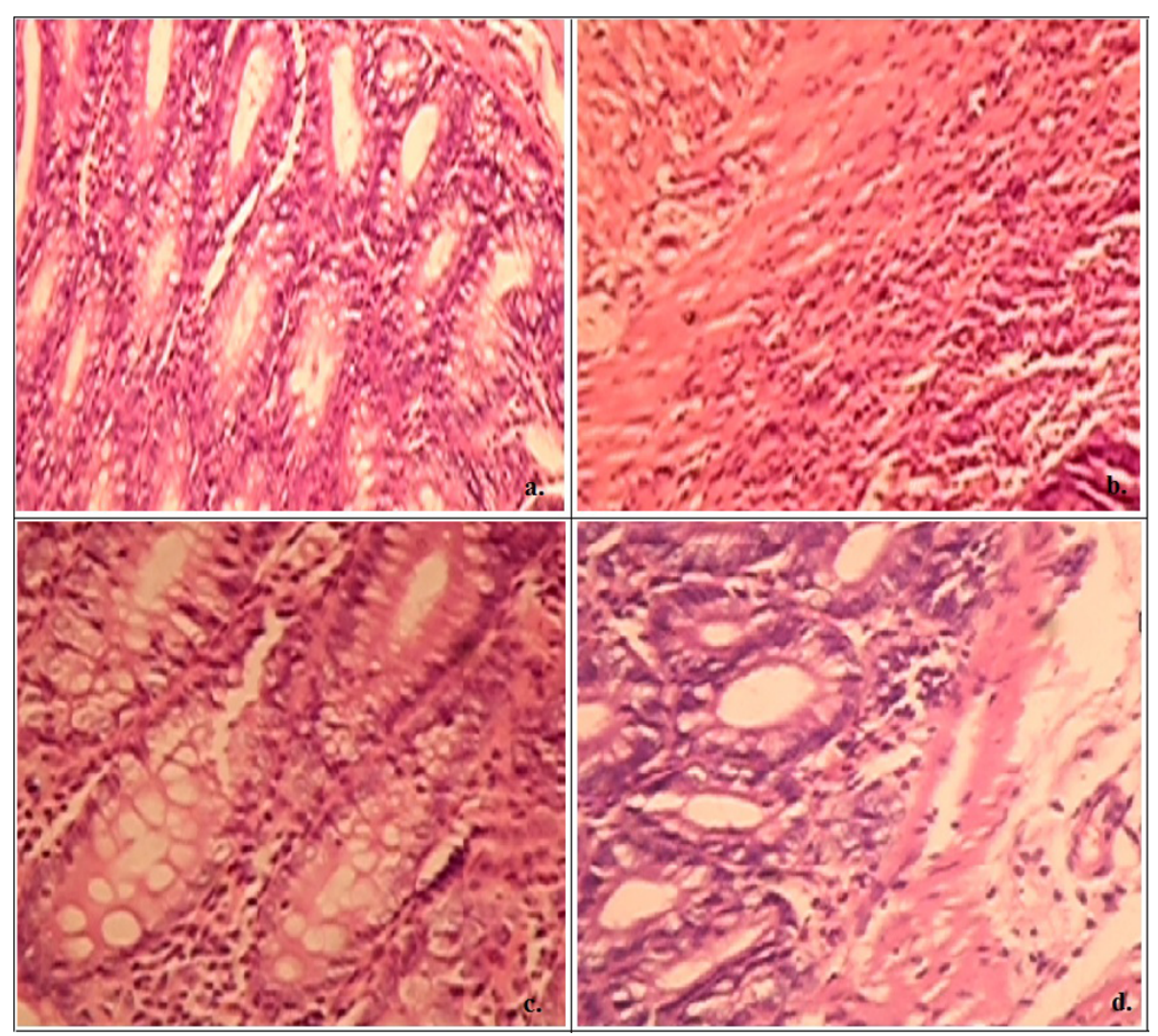

Figure 1 Histopathological features of colon section of a). healthy control rat, b). rat with TNBS treatment, c). rat with TNBS +WSREF treatment, d). rat with TNBS+Mesalamine treatment.

cells are mainly involved in inflammatory response and their activation forces them to aggregate and infiltrate the tissue, where they undergo respiratory burst, which increases their oxygen use resulting into oxidative damage to the tissue and triggers the production of pro-inflammatory cytokines, ROS and other mediators of inflammation [33].

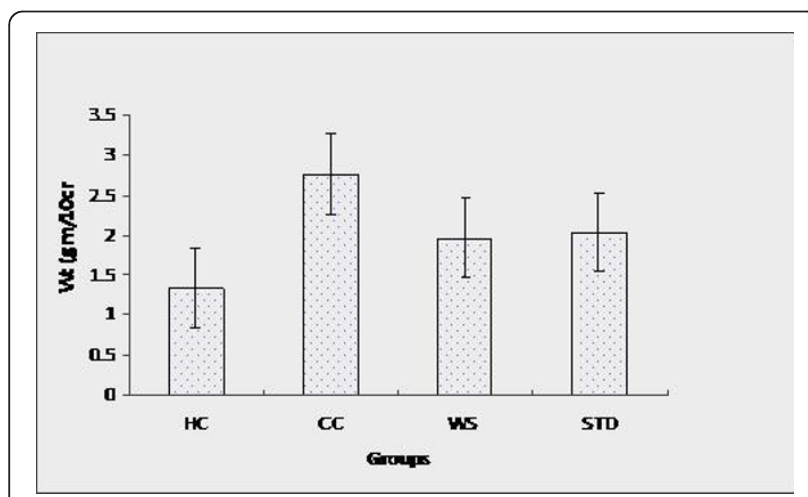

Figure 2 Change in colon weight as a function of period of treatment. HC: Healthy control, CC: Colitis control, WS: WSREF treated, STD: Standard (Mesalamine) control.
Initiation and perpetuation of inflammatory cascade by ROS causes subsequent tissue damage through the activation of nuclear factor kappa B (NF-kB), which is a ubiquitous transcription factor involved in the regulation of several genes in immune and inflammatory responses [34]. Oxidants are potent activators of NF-kB while the groups of structurally diverse anti-oxidants of herbal origin are capable of inhibiting NF-kB activation [35]. Human body has its own anti-oxidant defense system,

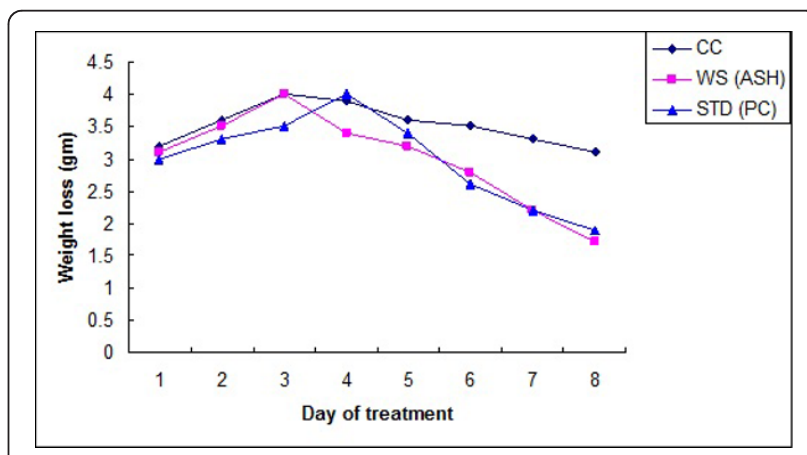

Figure 3 Change in rat weight as a function of period of treatment. 
which involves enzymes such as superoxide dismutases, catalases and glutathione peroxidases. However, this enzymatic anti-oxidant defense system is often not sufficient, leading to increased free radicals and oxidative damage ultimately resulting in severe inflammation and cell death [36].

The gastro-intestinal tract is a major site of generation of pro-oxidants, whose production is primarily due to the presence of plethora of microbes, food ingredients and interaction between immune cells. Not surprisingly, ROS has been implicated in the initiation and perpetuation of inflammatory disorders and pathogenesis of IBD. In one study, saliva of IBD patients were studied as an indicator of existence of oxidative and nitrosative stress. Excessive NO as well as higher levels of epidermal growth factor were found associated with the disease [37]. Similarly increased ROS in colon mucosa of UC patients was demonstrated $[38,39]$ and animal model exhibits increased oxidation and lipid peroxidation during initiation of colitis [40].

$W$. somnifera extract seems to be a balanced combination of biologically active ingredients as demonstrated by several workers. The cyto-protective and anti-inflammatory activity has protected experimental animals against the induced diseases. Antibacterial activity demonstrated by $W$. somnifera may also have significant role to play in IBD, especially for combating against the intestinal opportunistic pathogens known to play an important role in pathogenesis of IBD. Carminative and anti-diarrheal activity of $W$. somnifera may also be useful in restoring the disturbed gastro-intestinal mobility. Anti-oxidant activity is thought to play a central role in preventing inflammation as well restoration of mucosal lining. In the present study, aqueous extracts of W. somnifera roots have shown an excellent anti-oxidant activity, which is in total agreement with study carried out by Bhatnagar et al [41]. W. somnifera exhibits inhibition of (a) cyclooxygenase (b) activation of NF-kB induced inflammatory markers (like tumor necrosis factor alpha (TNF- $\alpha$ alpha) and interleukins) [42]. The withanolides constituting active ingredients of $W$. somnifera roots shows promising antibacterial, anti tumor, immunomodulating and anti-inflammatory properties [9].

Anti-ulcer activity of methanolic extract of W. somnifera and its action against stress pyloric ligation induced gastric ulcer in rats has been reported [41]. Treatment with $W$. somnifera extract $(100 \mathrm{mg} / \mathrm{kg} /$ day p.o.) for 15 days, significantly reduced volume of gastric secretion, free total acidity and ulcer index as compared to control group. Significant increase in total carbohydrates (TC) and its ratio to total protein (TP) was also observed, without significant change in total proteins. A significant increase in antioxidant enzymes (viz. catalase, superoxide dismutase (SOD)) and decrease in malondialdihyde
(MDA) was observed. Increased MDA levels after TNBS enema decreased upon treatment with $W$. somnifera formulation (Table 2). W. somnifera extract was found effective antiulcerogenic agent, comparable of ranitidine hydrochloride [41]. Treatment with W. somnifera formulation has shown decrease in macroscopic scores for the IBD. Histopathology examination of W. somnifera extract treated group revealed less damage compared to healthy animals (control group). Mesalamine treatment compared to $W$. somnifera formulation has shown significant and comparable protection in the rats in our study as revealed by the decreased colon weight and better gain in body weight. In the light of above properties, WSREF can potentially cure local inflammation, modulate immune system and can be a logical choice in relieving IBD symptoms. Administration of Iranian folk herbal medicines Ziziphora clinopoides and Teucrium persicum were reported to boost body's antioxidant mechanism such as SOD and catalase, with concomitant decrease in pro-inflammatory factors like TNF- $\alpha$ alpha, IL-1 $\beta$. These studies suggest potential dexterity of folk medicine in management of disease like IBD where free radicals and inflammation is the major pathophysiology $[43,44]$.

Success of herbal extracts in repairing tissue damage in experimental colitis could be enhanced by changing the route of administration. Several plant extracts have been reported beneficial in IBD, however, to our knowledge there is no report on a rectally applicable formulation. The pluronic rectal gel formulation impregnated with WSRE is in liquid form that is easy to apply as enema. At body temperature, it turns into a gel, which covers the rectum surface and due to its mucoadhesive property it forms a layer that persist and slowly release WSRE at the lesions in the rectum. This feature enhanced the beneficial effects of WSRE and resulted in reduced inflammation, faster healing and mucorestoration as revealed by the microscopic observations. Not all the extracts with good antioxidant activity could be beneficial in IBD. Harputluoglu et al [16] investigated oral application of Gingko biloba extract in acetic acidinduced colitis. Despite of an excellent antioxidant activity and antagonistic activity against platelets activating factor, (known to play a key role in pathogenesis of IBD), the extract failed to show noticeable recovery in experimental colitis. Based on the present data, topical application of aqueous extract of $W$. somnifera roots is strongly recommended in the treatment of distal colitis, especially for an early recovery in the damaged tissue. This data also substantiate the traditional way of treating colitis patients with enema of Ashwagandha extract. Detailed molecular study to identify the precise nature of active molecules will further assist in understanding their mechanism of action. 


\section{Conclusions}

This study affirms antioxidant potential of aqueous extract of roots of Withania somnifera and it's utility to ameliorate inflammation, which is the key pathology in IBD. The topical application in the form of rectal gel formulation proved to be as effective as the mesalamine treatment. In addition, WSREF showed marked mucorestoration and provides alternative strategy of practical significance for the treatment of Inflammatory Bowel Disease.

\section{Author details}

'Poona College of Pharmacy, Bharati Vidyapeeth University, Erandwane, Pune 411 023, India. Interactive Research School for Health Affairs, Bharati Vidyapeeth University, Pune-Satara Road, Pune 411 043, India.

\section{Authors' contributions}

PP, SG, SS and SJ carried out the study, designed experimental work, data collection and analysis. PP, SG and AH supervised the work and prepared the draft of manuscript. AP, KM and PK are involved evaluation of the data and corrected the manuscript. All the authors read and approved the final manuscript.

\section{Competing interests}

The authors declare that they have no competing interests.

Received: 14 July 2010 Accepted: 28 April 2011 Published: 28 April 2011

\section{References}

1. Bhattacharya A, Ghosal S, Bhattacharya SK: Anti-oxidant effect of Withania somnifera glycowithanolides in chronic footshock stress-induced perturbations of oxidative free radical scavenging enzymes and lipid peroxidation in rat frontal cortex and striatum. J Ethnopharmacol 2001, 74:1-6.

2. Tripathy AK, Shukla YN, Kumar S: W. somnifera [Withania somnifera] Dunal [Solanaceae]: A status report. J Med Arom Plant Sci 1996, 18:46-62.

3. Jayaprakasam B, Nair MG: Cyclooxygenase-2 inhibitory withanolides from leaves of Withania somnifera. Tetrahedron 2003, 59:841-849.

4. Jayaprakasam B, Strasburg GA, Nair MG: Potent lipid peroxidation inhibitors from Withania somnifera fruits. Tetrahedron 2004, 60:3109-3121.

5. Al-Hindwani MK, Al-Khafaji SH, Abdul-Nabi MH: Anti-granuloma activity of Iraqi Withania somnifera. J Ethnopharmacol 1992, 37:113-116.

6. Devi PU: Withania somnifera Dunal [W. somnifera]: Potential plant source of a promising drug for cancer chemotherapy and radiosensitization. Ind J Expt Biol 1996, 34:927-932.

7. Russo A, Izzo AA, Cardile V, Borrelli F, Vanella A: Indian medicinal plants as antiradicals and DNA cleavage protectors. Phytomed 2001, 8:125-132.

8. Rasool M, Marylatha L, Varalakshmi P: Effect of Withania somnifera on lysosomal acid hydrolases in adjuvant-induced arthritis in rats. Pharma Pharmacol Comm 2000, 6:187-190.

9. Rasool M, Varalakshmi P: Immunomodulatory role of Withania somnifera root powder on experimentally induced inflammation: An in vivo and in vitro study. Vascular Pharmacol 2006, 44:406-410.

10. Luvone T, Esposito G, Capasso F, Izzo A: Induction of nitric oxide synthase expression by Withania somnifera in macrophages. Life Sci 2003, 72:1617-1625.

11. Fiocchi C: Inflammatory bowel disease: etiology and pathogenesis. Gastroenterol 1998, 115:183-205.

12. Jagtap AG, Shirke SS, Phadke AS: Effect of polyherbal formulation on experimental models of inflammatory bowel diseases. J Ethnopharmacol 2004, 90:195-204.

13. Gurudu S, Fiocchi C, Katz JA: Inflammatory bowel disease. Best Pract Res Clin Gastroenterol 2002, 16:77-90.

14. Rezaie A, Parker RD, Abdollahi M: Oxidative stress and pathogenesis of inflammatory bowel disease: an epiphenomenon or the cause? Dig Dis Sci 2007, 52:2015-2021.
15. Pavlick KP, Laroux FS, Fuseler J, Wolf RE, Gray L, Hoffman J, Grisham MB: Role of reactive metabolites of oxygen and nitrogen in inflammatory bowel disease. Free Rad Biol Med 2002, 33:311-322.

16. Harputluoglu M, Demirel U, Yucel N, Karadag N, Temel I, Firat N, Ara C, Aladağ M, Karincaoğlu M, Hilmioğlu F: The effect of Gingko biloba extract on acetic acid on acetic acid induced colitis in rats. Turk $J$ Gastroenterol 2006, 17:177-182.

17. Miles AM, Grisham MB: Antioxidant properties of amino-salicylates. Methods Enzymol 1994, 234:555-572.

18. Rahimi R, Mozaffari S, Abdollahi M: On the use of herbal medicines in management of inflammatory bowel diseases: a systematic review of animal and human studies. Dig Dis Sci 2009, 54:471-480.

19. Sugimoto K, Hanai H, Tozawa K, Aoshi T, Uchijima M, Nagata T, Koide $Y$ : Curcumin prevents and ameliorates trinitrobenzenersulfonic acidinduced colitis in mice. Gastroenterol 2002, 123:1912-1922.

20. Ukil A, Maity S, Karmarkar S, Datta N, Vedasiromoni JR, Das PK: Curcumin, the major component of food flavour turmeric, reduces mucosal injury in trinitrobenzene sulphonic acid-induced colitis. $\mathrm{Br} J$ Pharmacol 2003 139:209-218

21. Salh B, Assi K, Templeman V, Parhar K, Owen D, Gomez-Munoz A Jacobson K: Curcumin attenuates DNB-induced murine colitis. Am J Physiol Gastrointest Liver Physiol 2003, 285:235-243.

22. Jian YT, Mai GF, Wang JD, Zhang YL, Luo RC, Fang YX: Preventive and therapeutic effects of NF-kappa B inhibitor curcumin in rats colitis induced by trinitrobenzene sulfonic acid. World J Gastroenterol 2005, 1:1747-1752

23. Shastry MK, Yadava RK, Singh RH: Effect of vasti therapy in the management of irritable bowel syndrome (Pakwasayagata vata Vyadhi). J Res Ayurveda Siddha 1996, 17:16-19.

24. Wade J, Van R: Quantitation of malonaldehyde [MDA] in plasma, by ionpairing reverse phase high performance liquid chromatography. Biochem Med 1985, 33:291-296.

25. Sreejayan N, Rao MNA: Nitric oxide scavenging by curcuminoids. J Pharm Pharmacol 1997, 49:105-107.

26. Ruch RJ, Cheng SJ, Klaunig JE: Prevention of Cytotoxicity and inhibition of intracellular communication by antioxidant catechins isolated from Chinese green tea. Carcinogenesis 1989, 10:1003-1008.

27. Mau EL: Antioxidant properties of several medicinal mushrooms. J Agri Food Chem 2002, 50:6072-6077

28. Elson CO, Sartor RB, Tennyson GS, Riddell RH: Experimental models of inflammatory bowel disease. Gastroenterol 1995, 109:1344-1367.

29. Wallace JL, Kinnan CM: An orally active inhibitor of leukotriene synthesis accelerates healing in a rat model of colitis. Am J Physiol 1990, 258:527-534.

30. Elson CO, Beagley KW, Sharmanov AT, Fujihashi K, Kiyono H, Tennyson GS, Cong Y, Black CA, Ridwan BW, McGhee JR: Hapten-induced model of murine inflammatory bowel disease: mucosal immune responses and protection by tolerance. J Immunol 1996, 157:2174-2185.

31. Neurath M, Fuss I, Kelshall B, Stuber E, Strober W: Antibodies to interleukin 12 abrogate established experimental colitis in mice. J Expt Med 1995 182:1281-1290.

32. Ilan Y, Weksler-Zangen S, Ben-Horin S, Diment J, Sauter B, Rahbani E, Engelhardt D, Chowdhury NR, Chowdhury JR, Goldin E: Treatment of experimental colitis by oral tolerance induction: A central role for suppressor lymphocytes. Am J Gastroenterol 2000, 95:966-973.

33. Devise MG, Hagen PO: Systemic inflammatory response syndrome. $\mathrm{Br} J$ Surg 1997, 84:920-935.

34. Siebenlist U, Franzoso G, Brown K: Regulation and function of NF-kappa B. Annual Rev Cell Biol 1994, 10:405-455.

35. Schreck R, Albermann K, Baeuerle PA: Nuclear factor kappa B: an oxidative stress-responsive transcription factor of eukaryotic cells [a review]. Free Radic Res Commun 1992, 17:221-237.

36. Halliwell B: Free radicals, anti-oxidants and human diseases: curiosity, cause or consequence. Lancet 1994, 344:721-724.

37. Jahanshahi G, Motavasel V, Rezaie A, Hashtroudi AA, Daryani NE, Abdollahi M: Alterations in antioxidant power and levels of epidermal growth factor and nitric oxide in saliva of patients with inflammatory bowel diseases. Dig Dis Sci 2004, 49:1752-1757.

38. Keshavarzian A, Sedghi S, Kanofsky J, List T, Robinson C, Ibrahim C, Winship D: Excessive production of reactive oxygen metabolites by 
inflammed colon: Analysis by chemi-luminescence probe. Gastroenterol 1992, 103:177-185.

39. Simmonds NJ, Allen RE, Stevens TR, van Someren RN, Blake DR,

Rampton DS: Chemiluminescence assay of mucosal reactive oxygen metabolites in inflammatory bowel disease. Gastroenterol 1992, 103:186-196.

40. Grisham MB, Volkmer C, Tso P, Yamada T: Metabolism of trinitrobenzene sulfonic acid by the rat colon produces reactive oxygen species. Gastroenterol 1991, 101:540-547.

41. Bhatnagar M, Sisodia SS, Bhatnagar R: Anti-ulcer and antioxidant activity of Asparagus racemosa WILD and Withania somnifera DUNAL in rats. Ann N Y Acad Sci 2005, 105:261-278.

42. Mishra $L C$, Singh BB, Dagenais S: Scientific basis for the therapeutic use of Withania somnifera [Ashwagandha]: A review. Alternative Med Rev 2000, 5:334-346.

43. Amini-Shirazi N, Hoseini A, Ranjbar A, Mohammadirad A, Khoshakhlagh P, Yasa N, Abdollahi M: Inhibition of tumor necrosis factor and nitrosative/ oxidative stresses by Ziziphora clinopoides (Kahlioti); a molecular mechanism of protection against dextran sodium sulfate-induced colitis in mice. Toxicol Mech Methods 2009, 19:183-189.

44. Abdolghaffari AH, Baghaei A, Moayer F, Esmaily H, Baeeri M, MonsefEsfahani HR, Hajiaghaee R, Abdollahi M: On the benefit of Teucrium in murine colitis through improvement of toxic inflammatory mediators. Hum Exp Toxicol 2010, 29:287-295.

\section{Pre-publication history}

The pre-publication history for this paper can be accessed here: http://www.biomedcentral.com/1472-6882/11/34/prepub

doi:10.1186/1472-6882-11-34

Cite this article as: Pawar et al:: Rectal gel application of Withania somnifera root extract expounds anti-inflammatory and mucorestorative activity in TNBS-induced Inflammatory Bowel Disease. BMC Complementary and Alternative Medicine 2011 11:34.

\section{Submit your next manuscript to BioMed Central and take full advantage of:}

- Convenient online submission

- Thorough peer review

- No space constraints or color figure charges

- Immediate publication on acceptance

- Inclusion in PubMed, CAS, Scopus and Google Scholar

- Research which is freely available for redistribution

Submit your manuscript at www.biomedcentral.com/submit
Biomed Central 